EESTI NSV TEADUSTE AKADEEMIA TOIMETISED. XVIII KOIDE

KEEMIA * GEOLOOGIA. 1969, NR. 3

ИЗВЕСТИЯ АКАДЕМИИ НАУК ЭСТОНСКОИ ССР. ТОМ ХVIII ХимИЯ - ГЕОЛОГИЯ. 1969, № 3

Л. ЛАХЕ, О. ЭИЗЕН

\title{
МЕТОДИКА АНАЛИЗА И ХИМИЧЕСКИЙ СОСТАВ СМОЛЫ, ЭКСТРАГИРОВАННОЙ ИЗ СЛАНЦЕВОГО КОКСА
}

Высококипящие фракции сланцевой смолы изучены с точки зрения их углеводородного группового состава и содержания кислородных соединений методом адсорбционной хроматографии на колонках $[1-3]$.

Проведены также определения составных частей топлива - карбоидов, мальтенов, асфальтенов [ $\left.{ }^{4}\right]$.

Химически однотипные соединения, например многоядерные ароматические углеводороды, разделяются по числу ядер методом тонкослойной хроматографии $\left[{ }^{5,6}\right]$. При групповом анализе рекомендуется трудоемкий метод адсорбционной хроматографии на колонках заменять тонкослойной хроматографией [ $\left.{ }^{7}\right]$

В настоящей работе анализ смеси по групповому составу проведен в тонких слоях окиси алюминия и силикагеля. Для определения высококипящей ароматики с конденсированными ядрами наряду с газо-жидкостной применялась и газо-адсорбционная хроматография. Существующие специфические и неспецифические силы адсорбции между анализируемым веществом и адсорбентом обусловливают иной характер раздсления веществ [8].

Целью настоящей работы является анализ углеводородных соединений, остающихся в коксе цеха коксования сланцеперерабатывающего комбината им. В. И. Ленина (г. Кохтла-Ярве), главным образом определение высококипящей ароматики.

\section{Экспериментальная часть}

Различные соединения в твердых продуктах термического разложения природных топлив определяются методом экстракции $\left[{ }^{9-11}\right]$.

В настоящей работе пробы кокса экстрагировались пиридином, бензолом или толуолом в экстракторе Сокслет. Қак показывают данные табл. 1, в опытах с пиридином сухого экстракта было получено $0,25 \%$, с бензолом - 0,15\%. Так как интерес представляла главным образом углеводородная часть соединений, то в дальнейшем пробы экстрагировались бензолом.

Количество вещества в экстракте пробы суммарного кокса не отражает состава отдельных зон куба с разным температурным режимом. Поэтому пробы отбирались из трех частей куба по 20 ка:

Данные экстракции суммарного кокса

\begin{tabular}{|c|c|c|c|}
\hline \multirow{2}{*}{$\begin{array}{c}\text { Раствори- } \\
\text { тель }\end{array}$} & \multirow{2}{*}{$\begin{array}{c}\text { Проба } \\
\text { кокса, } 2 \text { ? }\end{array}$} & \multicolumn{2}{|c|}{ Сухой экстракт } \\
\hline & & 2 & вес. $\%$ \\
\hline Пирид & & & 0,25 \\
\hline & & & \\
\hline Бензо & 300 & 2 & 0,21 \\
\hline DeH30 & & & $\begin{array}{l}0,10 \\
0,13\end{array}$ \\
\hline Толуол & 50,02 & 0,066 & 0,13 \\
\hline
\end{tabular}


около дверей (I), из поверхностного слоя (II) и середины коксового пирога (III), из которых для экстракции была взята средняя проба. Данные экстракции бензолом приведены в табл. 2. Наибольшее количество экстрагирующего вещества - 4,32\% содержится в сравнительно низкотемпературной части куба - около дверей (экстракт I). Минимальное количество экстрагирующего вещества содержится в поверхиостном слое кокса (экстракт II), откуда испарение веществ в ходе коксования самое интенсивное.

Полученные экстракты были проанализированы для определения их группового состава в тонких слоях окиси алюминия или силикагеля в таких же условиях, как и в опубликованной нами ранее работе $\left[{ }^{12}\right]$ -

Таблица 2

Данные экстракции бензолом кокса, взятого из отдельных зон куба коксования

\begin{tabular}{|c|c|c|c|c|c|}
\hline \multirow[b]{2}{*}{$\begin{array}{l}\text { Номер } \\
\text { пробы }\end{array}$} & \multirow{2}{*}{$\begin{array}{l}\text { Место } \\
\text { взятия } \\
\text { пробы } \\
\text { в кубе }\end{array}$} & \multirow[b]{2}{*}{$\begin{array}{l}\text { Әкстрагируе- } \\
\text { мый кокс, } 2\end{array}$} & \multirow[b]{2}{*}{ Бензол, $и л$} & \multicolumn{2}{|c|}{ Сухой әкстракт } \\
\hline & & & & 2 & вес. $\%$ \\
\hline I & & 750 & $6 \times 1000$ & 32,38 & 4,32 \\
\hline II & nal & 700 & $3 \times 1000$ & 0,72 & 0,095 \\
\hline III & 제 & 745 & $3 \times 1000$ & 1,57 & 0,29 \\
\hline
\end{tabular}

Тонкослойные фракции отмечали по их флоуресценции и анализировали газохроматографически. Распределение чистых эталонных веществ в тонком слое по их групповому составу показано на рис. 1. Как видно из рисунка, кислородсодержащие соединения остаются на обоих адсорбентах на стартовой линии и в примыкающей к ней фракции.

Подвижность ароматических соединений на двух адсорбентах значительно различается. Если на силикагеле ароматические соединения (двухъядерная ароматика; рис. $1 A$ ) остаются во фракции с $R_{f}=0,37$, то на окиси алюминия (рис. 1 Б) участок пластинки от $R_{f}=0,04$ до $R_{f}=0,68$ остается пустым и основная часть ароматических углеводородов содержится во фракции с $R_{f}=0,83$. Подобное распределение веществ дает возможность однократным разделением определить и многоядерную ароматику, имеющую значения $R_{f}$, соответствующие пустой части пластинки (значения $R_{f}$ для антрацена 0,62 , для пирена 0,68 , для 1,2-бензпирена $\left.0,38\left[{ }^{12}\right]\right)$.

Следует отметить, что при таком разделении сложной смеси в тонком слое ароматические углеводороды содержат примеси в виде олефинов-парафинов (см. рис. 1$)$. Значения $R_{f}$ олефинов близки к соответствующим значениям парафинов [ $\left.{ }^{7}\right]$.

Парафино-нафтеновая фракция находится на. силикагеле в конце пластинки и отделена от ароматической пустой частью пластинки. На окиси алюминия эта фракция примыкает к ароматике и содержит более подвижные соединения последней, например дифенилметан.

Состав описанных выше тонкослойных фракций анализировали газохроматографически на колонке длиной 3 м при 180 и $200^{\circ}$. Неподвиж- 


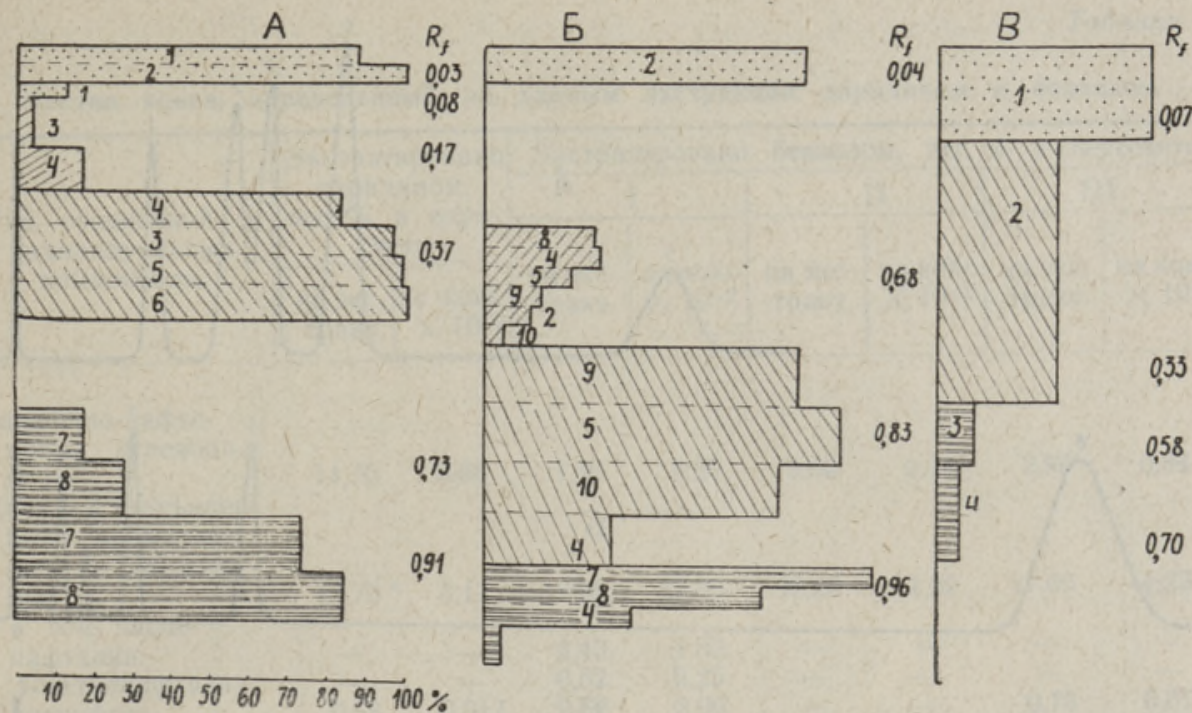

Рис. 1. Анализ группового состава сланцевой смолы тонкослойной хроматографией:

чистых веществ - $A$ - на силикагеле, $B-$ на окнси алюминия $(I-$ ацетофенон; $2-$ 2.3-диметнлфенол; 3 - дифенил; 4 - дифеннлметан; 5 - аценафтен; 6 - 1,5-днметилнафталнн; 7 - тетрадекан; 8 - днциклогексил; 9 - 3-метилдифеннл; 10 - 2,3-днметилнафталин) и экстракта пирндина $-B$.

ная фаза - $20 \%$ Реоплекс-400 на диатомите, газ-носитель - гелий со скоростью $60 \mathrm{~m} /$ мин, детектор - катарометр.

Тонкослойные фракции бензольных вытяжек кокса анализировались на двух колонках: 1) газо-адсорбционной, длиной 1,8 $M$, на специальном силикагеле при 180 и $\left.200^{\circ} ; 2\right)$ газо-жидкостной, длиной $3,4 \mu$, на $5 \% \mathrm{SE}-301$ на хромосорбе $G$, при $200^{\circ}$. Скорость потока гелия в обоих случаях $40 \mathrm{M} \Omega /$ мин.

Адсорбентом в газо-адсорбционной колонке служил специально обработанный водяным паром макропористый силикагель АТ-7 $\left[{ }^{8}\right]$ (размер зерен $0,25-0,50$ мм, диаметр пор $500 \AA$, объем пор 1,3 мл/2 и удельная поверхность $88 \mathrm{~m}^{2} / 2$ ). Адсорбент с такой сравнительно низкой удельной поверхностью годен и для анализа соединений, адсорбирующихся специфически и дающих координационные связи. Однако на промышлеңном необработанном силикагеле (удельная поверхность $175 \mathrm{~m}^{2} / \mathrm{e}$ ) получают узкие пики лишь для неспецифически адсорбирующихся веществ.

Ароматические соединения, разделенные главным образом по числу ядер, выходят из силикагелевой колонки сравнительно быстро (рис. 2). Кетоны и другие кислородсодержащие соединения, ввиду их специфической адсорбции, задерживаются.

С точки зрения высокотемпературной газовой хроматографии преимуществом газо-адсорбционной колонки является отсутствие жидкой фазы, так как последняя частично улетучивается из наполнителя. Поэтому спектры конденсатов компонентов, выходящих из колонки, часто искажены. Напротив, спектры компонентов из силикагелевой колонки имеют четкие характерные максимумы. Процентный состав фракций уточнялся методом газо-жидкостной хроматографии. 


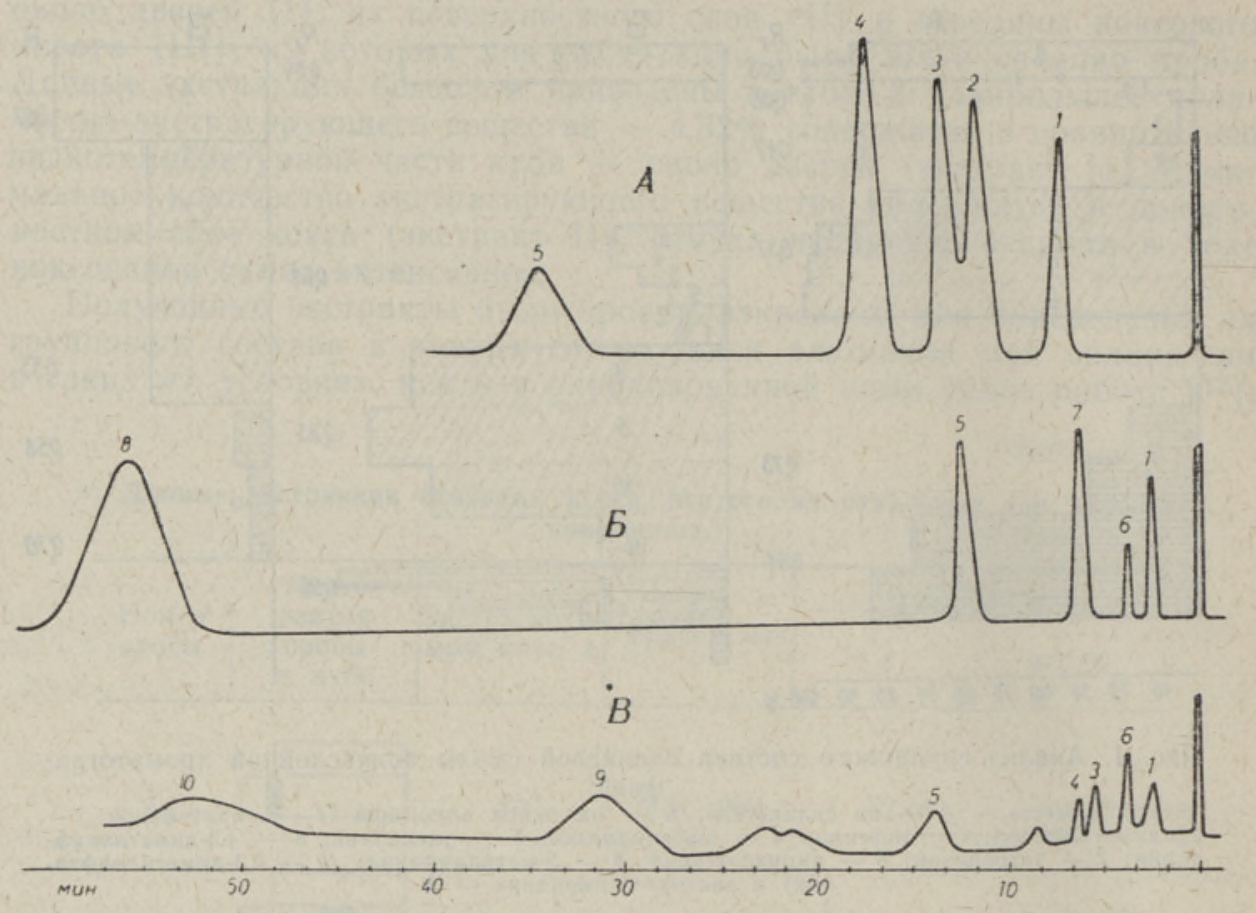

Рис. 2. Газо-адсорбционные хроматограммы чистых веществ $(A-$ при $180^{\circ}, \bar{B}-$ при $200^{\circ}$ ) и тонкослойной фракции 3 экстракта кокса I (см. рис. 1) $\left(\right.$ В - при $\left.200^{\circ}\right)$ :

1 - нафталин; 2 - дифенил; 3 - аценафтен; 4 - дифениленоксид; 5 - фенантрен: антрацен; 6 - 1-метилнафталин; 7 - диметилнафталин; 8 - бензофуран; 9 пирен + бразен; 10 - пронзводное пирена,

\section{Обсуждение результатов}

Данные по определению группового состава экстрактов кокса приведены в табл. 3 и на рис. 1 и 3, а характерные максимумы ультрафиолетовых спектров идентифицированных нами углеводородов - в табл. 4.

Экстракт пиридина анализировался в тонком слое силикагеля. Как показано на рис. $1 B$, парафино-нафтеновая часть находится во фракциях 3 и 4, ароматические углеводороды располагаются во фракции 2. Последняя разделена на растворимые в этаноле и бензоле части, в которых определены соединения с двумя-четырьмя ядрами. Содержание более тяжелой ароматики рассчитывалось по разнице. Доказательством наличия соединений с пятью и более ядрами является ультрафиолетовый спектр фракции с началом поглощения при 420 ммк и участком постоянного значения поглощения от 380 до 385 ммк.

Из-за большого числа заместителей характерные максимумы в спектре сливаются.

Очевидно, в боковых цепях тяжелой ароматики преобладают нафтеновые кольца, так как метилпроизводные для продуктов длительной термической обработки уже не характерны [2].

Для более подробного анализа ароматических соединений экстракта пиридина потребовалось большее количество исходной фракции. Кислород- и серусодержащие соединения, составляющие $54,6 \%$ от экстракта, остаются на стартовой линии. 
Таблица 3

Состав кокса, определенный по данным экстракции пиридином и бензолом

\begin{tabular}{|c|c|c|c|c|c|c|c|}
\hline \multirow{4}{*}{$\begin{array}{c}\text { Тип соединения и } \\
\text { нндивидуальные } \\
\text { компоненты }\end{array}$} & \multirow{3}{*}{$\begin{array}{l}\text { Экстрагировано } \\
\text { пиридином, } \\
\text { вес. \% в пере- } \\
\text { счете } \\
\end{array}$} & \multicolumn{2}{|c|}{ Экстрагировано } & \multicolumn{4}{|c|}{ бензолом, вес. \% в пересчете } \\
\hline & & \multicolumn{2}{|r|}{ I } & \multicolumn{2}{|c|}{ II } & \multicolumn{2}{|c|}{ III } \\
\hline & & & & & & & \\
\hline & $\begin{array}{c}\text { на экс- на кокс } \\
\text { тракт } \times 10^{-2}\end{array}$ & $\begin{array}{l}\text { на экс- } \\
\text { тракт }\end{array}$ & $\begin{array}{l}\text { на кокс } \\
\times 10^{-2}\end{array}$ & $\begin{array}{l}\text { на экс- } \\
\text { тракт }\end{array}$ & $\begin{array}{l}\text { на кокс } \\
\times 10^{-2}\end{array}$ & $\begin{array}{l}\text { на экс- } \\
\text { тракт }\end{array}$ & $\begin{array}{r}\text { на кокс } \\
\times 10^{-2}\end{array}$ \\
\hline
\end{tabular}

Парафино-нафте-

новые углеводо-

роды

Двухъ- и трехъядер-

$\begin{array}{llllllll}14,70 & 3,68 & 1,80 & 8,00 & 3,60 & 0,34 & 2,90 & 0,84\end{array}$

ные ароматиче-

ские углеводоро-

ды,

в том числе:

нафталин

1-метилнафталин

аценафтен

дифениленоксид

антрацен

фенантрен

3,68

8,00

3,60

2,90

0,84

Четырехъядерные

ароматические

углеводороды,

в том числе:

пирен

бразан

$12,70 * \quad 3,17 \quad 12,00$

52,00

12.20

$1,22 \quad 17,00$

4,93

$\begin{array}{lll}- & - & 0,43 \\ \overline{0,68} & 0,017 & 0,52 \\ 4,70 & 1,17 & 0,43 \\ 6,20 & 1,55 & 1,26\end{array}$

\section{1,85}

2,25

2,90

1,85

$\begin{array}{llll}- & \bar{E} & \overline{-} & \overline{-} \\ - & \bar{E} & \overline{0,78} & 0,07\end{array}$

5,44

5,63

0,56

$1,68 \quad 0,17$

производные пирена

Соединения типа бензпирена,

в том числе:

3,4-бензпирен

Соединения с пятью и более ядрами

Кнслород- и серусодержащие соединения

$\begin{array}{rrrrrrrr}- & - & 17,0 & 74 & 9,40 & 0,94 & 12,70 & 3,67 \\ 1,13 & 0,28 & 4,05 & 17,50 & - & - & 0,82 & 0,08 \\ - & - & 3,02 & 13,05 & - & - & - & - \\ - & - & 10,10 & 43,00 & 9,70 & 0,97 & 11,10 & 3,22 \\ - & - & 0,045 & 0,19 & - & - & - & - \\ 18,00 & 4,50 & 12,90 & 56,00 & 25,00 & 2,50 & 13,10 & 3,77 \\ 54,60 & 13,70 & 46,20 & 199,00 & 40,10 & 3,83 & 43,20 & 16,85\end{array}$

* Содержит четырехъядерную ароматику.

Вытяжки бензола анализировались в тонком слое окиси алюминия (рис. 3 I, II и III). Фракция 2 экстракта I наносилась вторично на тонкий слой (рис. 3 I/2). Как показывает тонкослойный анализ, парафино-нафтеновая часть находится на конце пластинки со значением $R_{f}=$ $=0,95-0,91$ и содержит некоторые примеси 2-3-ядерной ароматики. Основная часть последней сосредоточена во фракции 5 с $R_{f}=0,69-0,61$. Трехъядерная ароматика при анализе смол со-
Таблица 4

Спектральная характеристика ароматических соединений в ультрафиолете

\begin{tabular}{c|c}
\hline $\begin{array}{c}\text { Идентифици- } \\
\text { рованные } \\
\text { соединения }\end{array}$ & $\begin{array}{c}\text { Характерные максимумы } \\
\text { спектров, ммк }\end{array}$ \\
\hline
\end{tabular}

Нафталин

1-Метилнафта-

лин

Аценафтен

Дифениленоксид

Антрацен

Фенантрен

Пирен

Бразан

3,4-Бензпирен
319311301297285275

322314291282271

320306300

292280250

$\begin{array}{lllll}375 & 355 & 338 & 322 & 253\end{array}$

$\begin{array}{llllll}333 & 318 & 305 & 292 & 275 & 262\end{array}$

$350331272 \quad 260250$

403385364 $\begin{array}{llllll}345 & 338 & 330 & 292 & 281 & 274\end{array}$ 


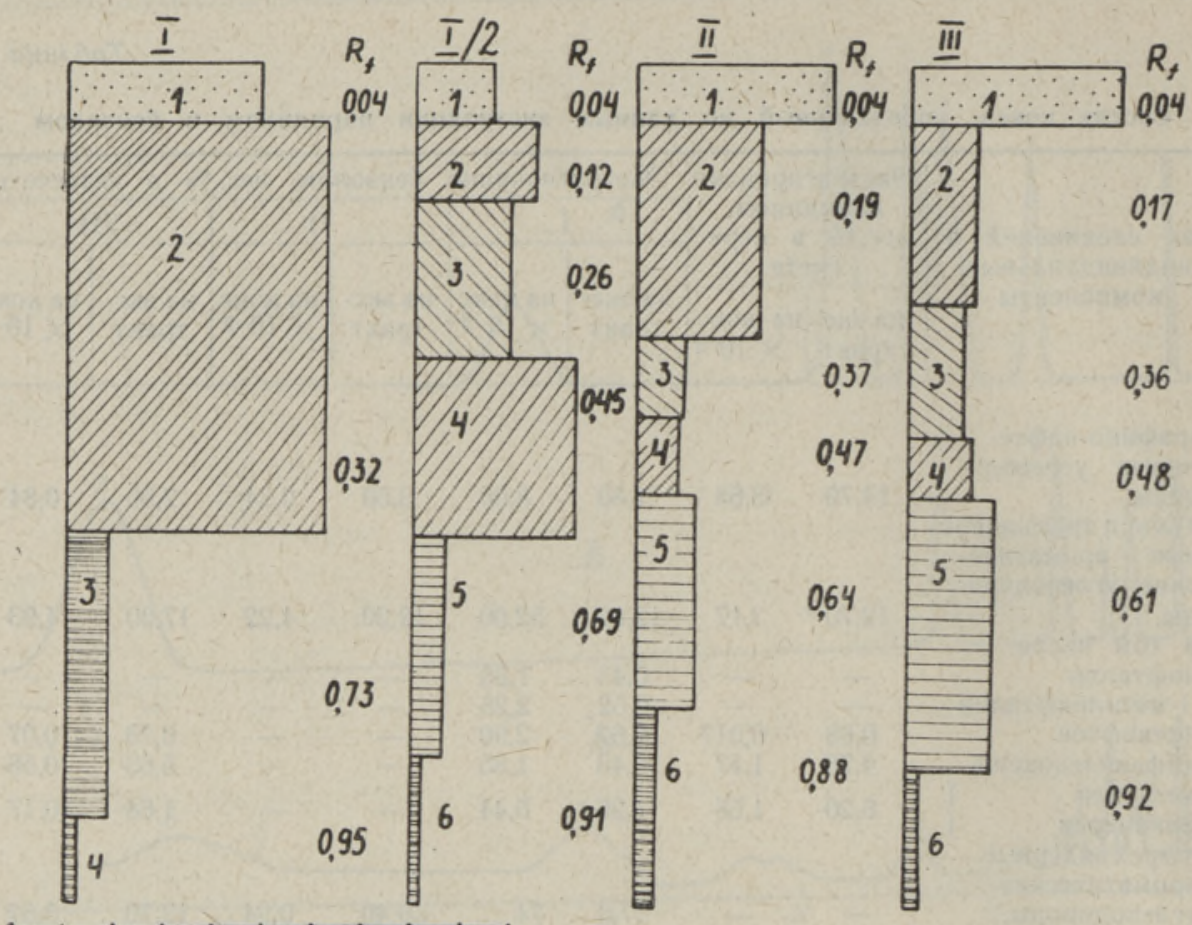

$10 \quad 20 \quad 30 \quad 40 \quad 50 \quad 60 \quad 70 \quad 80 \quad 90 \quad 100 \%$

Рис. 3. Распределение экстрактов бензола (I, II и III) по групповому составу в тонком слое окиси алюминия: $1-6-$ фракции.

держит немного четырехъядерной, что вызывает уменьшение значения $R_{f}$ данной фракции по сравнению с чистыми веществами.

Четырехъядерная ароматика находится во фракции 4 с $R_{f}=0,48$ (трифенил имеет $R_{f}=0,45$ ).

Соединения типа бензпирена находятся во фракции 3 с $R_{f}=$ $=0,26-0,36$.

Смолистые соединения, более тяжелые, чем пятиядерная ароматика, остаются во второй фракции. Кислород- и серусодержащие соединения находятся на стартовой линии и на окиси алюминия. Содержание серы, определенное в экстракте I по методу Гроте, составляет $0,52 \%$ от экстракта.

Процентный состав тонкослойных фракций по отдельным классам соединений приведен в табл. 3. По данным таблицы, в пробе кокса I содержится $2,25 \%$ соединений ароматического характера, из них углеводородов типа бензпирена - $19,1 \%$ и более тяжелой ароматики $24,8 \%$. Из канцерогенных соединений после двукратной очистки бензпиреновой фракции был идентифицирован спектрофотометрическим методом 3,4-бензпирен, который составлял $0,045 \%$ от экстракта I и в пере счете на кокс I - 0,0019\%.

Из более легких индивидуальных соединений определены нафталин, метилнафталин, аценафтен, антрацен, фенантрен, пирен и соединения с эфирной связью в ароматической молекуле - дифениленоксид и бразан. 
Как показывают приведенные выше данные, количество экстрагирующихся из кокса соединений ароматического характера зависит от температуры в отдельных зонах куба коксования и составляет от $4,32 \%$ до полученного нами минимального значения - $0,1 \%$.

\section{Л И ТЕРА Т У Р А}

1. Х юссе Ю. Ю., Химическая характеристика высших фракций генераторной смолы прнбалтийского сланца, Тарту, 1949.

2. Эй зен О. Г., Тр. ТПИ, Сер. А, № 63, 82 (1955).

3. Гуля ева Л. И., Пышкина Н. И., Химия и технологня горючих сланцев и продуктов их переработки, Тр. ВНИИПС, вып. 4, 137 (1955).

4. Иоонас Р. Э., Леэпер Р. А., Серебрянников Н. Д., Эйги К. Р., Добыча и переработка горючих сланцев, вып. 15, 217 (1966).

5. Arro I., ENSV TA Toimet., Füüs.-Mat. ja Tehn. Tead. Seeria, 13, nr. 1, 23 (1964),

6. Э й з ен О., Р а уд д Х., Изв. АН ЭССР, Сер. физ.-матем. и техн, наук, 14, № 4, 631 (1965).

7. Клесмент И., К асберг А., Эйзен О., Изв. АН ЭССР, Сер. физ.-матем, и техн. наук, 15, № 1,98 (1966).

8. N i k it in Ju. S., Gas-Chromatographie, Berlin, 1968, S. 391.

9. Franck H. G., Brennstoff-Chemie, 36, Nr. 1/2, 12 (1955).

10. Halleux, A., Delavarenne S., Tschamler H., Nature, 190, No. 4774, 437 (1961).

11. Ruiter E. de, Erdöl und Kohle, 18, Nr. 8, 625 (1965).

12. Л ахе Л., Эй зен О., Изв. АН ЭССР, Хим. Геол., 17, № 1, 30 (1968).

$\begin{array}{cc}\text { Институт химии } & \text { Поступила в редакцию } \\ \text { Академии наук Эстонской ССР } & 5 / \mathrm{VII} 1968\end{array}$

L. LAHE, O. EISEN

\section{POLLVKIVIKOKSIST EKSTRAHEERITUD TÕRVA ANALUUSI METOODIKA JA KEEMILINE KOOSTIS}

Tõrva grupikoostis määrati ōhukese kihi kromatograafia ja gaasikromatograafia abii. Leiti, et koks sisaldab $2,25 \%$ aromaatseid ühendeid, millest $19,1 \%$ on benspüreeni tüüpi, $24,8 \%$ aga enam kui 5-tuumaline aromaatika. Koks sisaldab 0,0019\% 3,4-benspüreeni.

\section{LAHE, O. EISEN}

\section{METHODIK DER ANALYSE UND CHEMISCHE ZUSAMMENSETZUNG DES AUS KOKS EXTRAHIERTEN TEERES}

Es wurde mittels Dünnschicht- und Gaschromatographie die Gruppenzusammensetzung des aus Koks extrahierten schweren Teeres untersucht. Man hat gefunden, da der Koks 2,25\% aromatische Kohlenwasserstoffe enthält, von denen 19,1\% BenzpyrenStrukturen und $24,8 \%$ mehr als fünfkernige Strukturen aufweisen. Sein Gehalt an 3,4-Benzpyren ist $0,0019 \%$. 